\title{
Accelerating Implementation of Shared Decision-Making in the Netherlands: An Exploratory Investigation
}

Haske van Veenendaal ${ }^{1}$, researcher and consultant in shared decision-making, Trudy van der Weijden ${ }^{2}$, professor, Dirk T Ubbink ${ }^{3}$, professor, Anne M Stiggelbout ${ }^{4}$, professor, Linda A van Mierlo ${ }^{5}$, program manager, Carina G J M Hilders ${ }^{1,6}$, professor and medical director.

1. Erasmus School of Health Policy \& Management, Erasmus University Rotterdam, P.O. Box 1738, 3000 DR Rotterdam, the Netherlands. haskevanveenendaal@gmail.com.

2. Department of Family Medicine, CAPHRI, Maastricht University Medical Centre, PO Box 616, 6200 MD Maastricht, The Netherlands. trudy.vanderweijden@maastrichtuniversity.nl.

3. Department of Surgery, Amsterdam University Medical Centers, Meibergdreef 9, 1105 AZ Amsterdam, The Netherlands. d.ubbink@amc.nl.

4. Medical Decision Making, Department of Biomedical Data Sciences, Leiden University Medical Centre, Post zone J10-S, Postbus 9600, 2300 RC Leiden, The Netherlands. a.m.stiggelbout@lumc.nl.

5. Department of Innovation, CZ Healthcare Insurance, Postbus 90152, 5000 LD Tilburg, The Netherlands. lindavanmierlo@hotmail.com.

6. Board of directors, Reinier de Graaf Hospital, Reinier de Graafweg 5, 2625 AD Delft, The Netherlands. c.hilders@rdgg.nl.

\section{Correspondence to:}

$\mathrm{H}$ van Veenendaal, Erasmus School of Health Policy \& Management, Erasmus University Rotterdam, P.O. Box 1738, 3000 DR Rotterdam, the Netherlands.

Telephone +31-651952029

haskevanveenendaal@gmail.com. 


\section{Abstract}

\section{Objective}

To prioritize strategies to implement shared decision-making (SDM) in daily practice, resulting in an agenda for a nationwide approach.

\section{Methods}

This was a qualitative, exploratory investigation involving: Interviews $(N=43)$ to elicit perceived barriers to and facilitators of change, focus group discussions $(N=51)$ to develop an implementation strategy, and re-affirmation through written feedback $(n=19)$. Professionals, patients, researchers and policymakers from different healthcare sectors participated.

Determinants for change were addressed at four implementation levels: (1) the concept of SDM, (2) clinician and/or patient, (3) organizational context and (4) socio-political context.

\section{Results}

Following the identification of perceived barriers, four strategies were proposed to scale up SDM: 1) stimulating intrinsic motivation among clinicians via an integrated programmatic approach, 2) training and implementation in routine practice, 3) stimulating the empowerment of patients, 4) creating an enabling socio-political context.

\section{Conclusion}

Clinicians mentioned that applying SDM makes their job more rewarding and indicated that implementation in daily practice needs ground-up redesign. The challenge is to effectively influence the behavior of clinicians and patients alike, and adapt clinical pathways to facilitate the exploration of patient values.

\section{Practice Implications}

Stakeholders should connect nationwide initiatives to pool information, and make the healthcare system supportive of implementing SDM. 


\section{Introduction}

Shared decision-making (SDM) combines patient-centered communication skills with evidencebased medicine to achieve high-quality patient care [1]. It facilitates a process of collaboration and deliberation, based on "team talk," "option talk," and "decision talk" [2]. Professionals may use several steps and accompanying communication strategies to implement SDM [3]. While there is convincing evidence for the use of patient decision aids to support SDM [4], most of these aids have not subsequently been implemented in the complexity of clinical practice. Observed levels of patient involvement during clinical consultations suggest there is considerable room for improvement [5].

Tailored interventions can be used to overcome barriers and enable the desired change [6], [7], [8], [9], [10]. Barriers to and facilitators of implementation - or determinants for change - can occur at four implementation levels: (1) the innovation (the concept of SDM), (2) users of the innovation, (3) organizational context and (4) socio-political context [10]. Considering each of these levels increases the likelihood of designing an effective implementation of change [9], [10], [11]. With regard to the concept of SDM (1), opinions differ about what SDM entails and how best to put it into practice [2], [12]. At the level of the patient (2), an inability or lack of motivation to appraise information can hinder SDM [13]. Patients are reluctant to actively participate in consultations, as they worry about being inadequate, bothersome, or claiming too much time [14]. Patients often think that "the doctor knows best" and do not feel that it is important to contribute their personal preferences/circumstances [15]. Among clinicians (2), prominent barriers include time constraints and a perceived lack of applicability due to patient characteristics or the clinical situation [16]. Changing the attitudes and behavior of clinicians is seen to be key to the implementation of SDM, because while many clinicians think that they already involve patients in decisions, others do not view SDM as core to their clinical role [17]. A barrier at the organizational level (3) is clinician concern about current workflow disruption [18]. The lack of incentives that stimulate the adoption of SDM in practice has been noted as a sociopolitical barrier (4) to implementation [18]. 
Training clinicians, empowering patients, making high-quality patient decision aids easily accessible, and creating feedback through rewarding incentives could boost the uptake of SDM in healthcare [15], [16], [17], [19] [20], [21], [22], [23], [24], [25]. The Dutch government, healthcare insurers, professional societies and patient bodies have actively supported the implementation of SDM either in policy statements or by financing implementation initiatives. They too report a lack of guidance about how to adopt SDM in routine practice [26]. The aim of our investigation was therefore to formulate and prioritize strategies for the implementation of SDM, based on identification of barriers for change, and resulting in an agenda for a nationwide approach. We selected frontrunners in SDM implementation from various backgrounds to involve participants who can speak from experience. Having overcome barriers for change, we thought that they could help us to understand what it takes to successfully apply SDM in daily practice. This may yield new insights into how effective implementation in a local context can be aligned with a nationwide approach. 


\section{Methods}

\subsection{Study design}

This qualitative exploration used different methods to enhance data validity [27], in line with the Standards for Reporting Qualitative Studies (SRQR) [28]. Semi-structured interviews, focus groups, and re-affirmation through written feedback were applied to explore how implementation can be accelerated. We combined individual interviews with two large focus groups to collect indepth knowledge about SDM implementation in daily practice from different perspectives. Key

literature [15], [16], [19], [20], [21], [22], [23] on barriers to and facilitators for implementing SDM was used to prepare the interviews, focus groups and reports, overseen by a six-member steering group. The interview guide, developed by the researchers $(\mathrm{HV}, \mathrm{GH})$ following discussion with the steering group, is shown in the Appendix.

\subsection{Participants}

We recruited Dutch SDM experts in the period between January 2015 and April 2016. We used purposeful sampling [29], [30] for the identification and selection of clinicians from different healthcare areas, researchers, patient advocates and policymakers (all knowledgeable in SDM implementation, i.e. integrating decisions aids locally, training SDM, adapting clinical pathways, or creating (local or national) preconditions for SDM implementation).

A list of eligible candidates $(\mathrm{N}=35)$ for the interviews and two focus groups $(\mathrm{N}=58)$ were drawn up by the steering group. All participants were employed in primary and secondary healthcare (including mental healthcare), long-term care, patient advocacy, policymaking (including healthcare insurance), management, research, or in companies that develop or implement decision aids. Recruitment of participants continued until the investigators concluded that participants no longer provided new insights. Four additional participants were recruited in the course of the study based on the recommendations of participants, to cover adjacent areas such as ethics. 


\subsection{Procedures and data analysis}

Face-to-face or telephone interviews were carried out to identify barriers for implementation. Participants were asked to (a) describe promising regional and national SDM initiatives, (b) describe barriers for implementation, and (c) suggest who should be involved in overcoming these barriers. Second, two focus groups were conducted to (d) categorize and prioritize activities in accelerating the implementation of SDM and (e) to use this information to draw up a supportive national agenda. Participants were (f) asked to suggest stakeholders for carrying out these activities.

Full verbatim transcripts were not made. Interviews were summarized as field notes and focus groups as written meeting minutes $(\mathrm{HV}, \mathrm{GH})$ and checked by the participants. These notes were read by one investigator, who then independently analyzed meaningful observations using the determinant framework [10]. After analyzing the interviews, two investigators selected discussion themes for the focus groups. The first focus group $(n=27)$ was geared towards hospital care, the second $(n=24)$ was expanded to general practice, mental healthcare and longterm care. Both focus groups lasted 3 hours (with a 30-minute break). If participants were unable to attend the meeting, they arranged a replacement. Preliminary results of the interviews were presented during the focus groups; presentation of key findings was followed by an indepth discussion about which implementation approach appeared to be most effective.

After the second focus group, overarching concepts were described in a draft report and discussed in the steering group, together with the meeting minutes, in order to identify key elements for a Dutch national agenda to scale up SDM. This resulted in a second draft report, which was then sent for feedback to all participants, and subsequently finalized in version 3. 


\section{Results}

\subsection{Participants}

Forty-three interviews, 23 face-to-face and 20 by telephone, were carried out (Table A.1) with a $100 \%$ response rate. Clinicians (33\%) and researchers (35\%) were strongly represented in the interviews. A total of 51 participants who were knowledgeable in SDM implementation attended two focus groups. Of the 30 participants invited to join the first focus group, 27 (90\%) attended. Two participants had previously been interviewed. Participants were all employed by hospitals, and the topic therefore focused on hospital care. Of the 24 participants (out of 28 invited; $86 \%$ ) in the second focus group, nine (28\%) had been previously interviewed. The majority $(64 \%)$ of the participants worked in a clinical setting. The remainder (36\%) worked in general practice, mental healthcare, or long-term care. Nineteen participants provided a total of 75 written comments on the (draft) study findings. Participants' comments and text changes proposed by the researchers $(\mathrm{HV}, \mathrm{GH})$ were distributed to the participants before finalizing the text. Analysis of the data and writing of the report took place from May 2016 to December 2016.

\subsection{Barriers for the implementation of SDM}

Barriers for implementation as indicated in the interviews are provided in Table A.2. All groups of participants indicated that the lack of clarity about what SDM entails is felt more prominently by clinicians and patients than by managers and policymakers. Participants highlighted the risk that SDM is merely seen to involve the provision of decision aids to patients. The application of SDM was perceived to enhance work satisfaction and the relationship between clinicians and patients. Clinicians were unclear about the type of decisions/consultations SDM could be advantageous for. Especially within the group of clinicians, misjudgment of the patients' preferences, lack of knowledge about what sharing decisions for one's behavior in daily practice means, lack of skills, and a lack of role models were all perceived to be relevant factors. Motivated clinicians experienced barriers within the organization when applying SDM; poor team- and management-support; lack of valid and clear patient information or high-quality decision aids, national guidelines that recommend only one option; and the failure of 
policymakers and external bodies to effectively support SDM. Moreover, the instruments that clinicians use for quality assurance - accreditation, and process redesign - were found to be unsuitable for SDM. Clinicians noted that quality instruments focus on standardizing and increasing efficiency rather than having an eye for the individual differences between patients and incorporating these in the process of decision-making in practice.

\subsection{Designing a nationwide approach to the implementation of SDM}

From the focus groups, it became clear that an integrated approach for implementation was preferable to a more straightforward 'barrier-solution approach'. Experts indicated that a successful strategy requires different stakeholders working at different implementation levels simultaneously. By integrating strategies in overarching elements, a shared ambition becomes feasible and stakeholders can contribute in their own way and at their own pace. The following implementation strategies were identified, comprising four elements addressing several of the four implementation levels, and involving different stakeholders for each strategy (Table A.3).

\section{An integrated programmatic approach to build intrinsic motivation}

Fragmented but promising initiatives should be connected on a national scale in order to pool information and speed up the exchange of lessons learned regarding implementation. Participants emphasized the importance of the intrinsic motivation of clinicians as SDM was perceived as making the clinician's profession more fun and challenging. The challenge remains how to appeal to - and leverage - clinicians' values and professional motivation to deliver truly patient-centered care. This could emerge as a key driver for clinicians to let go of old habits and change care processes to better accommodate individual patient preferences, both in their teams and in their organizations.

Relevant parties surrounding clinical practice must also support implementation. Professional bodies, patient organizations, healthcare insurance companies, managers and government, should all monitor the progress of implementation and continuously strive to connect initiatives without slowing each other down because of their own delays and barriers. Inter-professional 
training targeting clinicians to help them understand which competencies are needed to apply SDM in daily practice, should be incorporated into professional curricula and training programs. Simplistic financial incentives based on 'box-checking' behavior demotivate clinicians. National parties could facilitate the implementation of SDM e.g. by putting innovators in the spotlight, adapting quality instruments (guidelines, standards, accreditation, process redesign) and professional role descriptions, providing financial incentives such as reimbursement of extended or extra consultations, and incorporating technological innovation (e.g. providing patients access to their medical records, question prompting, and tailored patient information services).

\section{Training and implementation of SDM in routine practice}

Participants indicated that future implementation initiatives in clinical practice should engage a new group of clinicians, patients, and policymakers, i.e. both the early and late adopters, to make SDM part of usual care. Pivotal to this implementation would be a consideration of working mechanisms in specific local contexts with a focus on process redesign and professional behavior that supports the application of SDM in daily practice (i.e. by giving feedback to clinicians on their actual SDM performance). These experiments should focus on measuring the process of implementation in routine practice rather than proving the effectiveness of SDM once again.

Knowledge-sharing should be reinforced by including SDM in audits and regional network meetings, especially knowledge of process (re)design, Thus, we need to learn how to design local care pathways that facilitate time-outs for patients to process information and clarify preferences in decision-making, rather than merely improve efficiency. This would encompass several issues related to the scheduling of appointments, the effective use of decision tools and patient records, how clinicians work in a team (and contribute to multidisciplinary consultations), and who communicates what during the patient journey. National guidelines and other standards should be adjusted, and recommendations should highlight preference-sensitive decisions, indicating uncertainty and facilitating option awareness by describing alternative options. 
Participants stressed that training will be vital in order to overcome the belief among clinicians that applying SDM does not differ much from their current practice. Effective training methods should include reflective elements and video/audio-feedback on the clinicians' performance. Feedback should be non-judgmental and individual, in order to help clinicians understand what exactly SDM means for their own daily practice. These individual training modules could be combined with e-learning, role play, workplace learning, and group discussions. The involvement of senior professionals in the training would be mutually beneficial.

\section{Stimulating the empowerment of patients and citizens}

Participants emphasized that citizens and patients alike need to know what SDM involves and why it might help. A national campaign, such as 'Ask 3 Questions', might convince patients about their role in decision-making and may encourage their clinicians to apply SDM. Patient records should become available and high-quality patient decision-making support tools for a significant number of health problems, should be made accessible via a public platform. Guideline recommendations could be linked to decision aids, integrated with patient records, and connected to clinical pathways. A Dutch guideline has been developed to define quality criteria for the development decision support tools, in alignment with clinical guidelines.

Involving patients at the micro-, meso- and macro-levels, before, during and after implementation of SDM, should become standard procedure. Developing professional education should ideally include the participation of patient advocates and vice versa. Development of decision-making support tools should also be a joint effort involving patients and clinicians.

\section{Creating a rewarding socio-political context}

Participants could not point out exactly which socio-political issues hinder or facilitate them in terms of applying SDM but did indicate that promising SDM initiatives were held back by logistical, financial, and administrative factors. Stakeholders may wish to implement instruments that are often theoretically sound, but unknown and unfit for use in local practice. Clinicians felt 
that they had received insufficient support from directors, managers and policymakers in terms of adapting legislation to facilitate implementation of SDM in the consulting room. A real step forward requires local managers and leaders to enable a change of culture in which patient values and quality of life are the key drivers for health care delivery, and rules, standards and $\underline{\text { regulations are implemented accordingly. Performance indicators, including observation of }}$ consultations, can provide insights into team performance regarding SDM. These indicators can $\underline{\text { be used for improvement and also for governance, external review, and to design and }}$ implement supportive financial incentives. Respondents also proposed that general practitioners should get more time to coach patients, including those who are treated in hospital. Managers can play an important role by anticipating budget shifts, facilitate the redesign of care pathways, using supportive information technology, redistributing tasks between team members, and being more flexible with regard to guideline recommendations and other regulations that are imposed by external stakeholders. On a regional or national level, incentives such as the reimbursement of extra consultations as part of a programmatic approach are required. 


\section{Discussion and conclusion}

\subsection{Discussion}

In the Netherlands, SDM is a topic of active debate [26], [31]. Our exploratory study yielded strategies to foster a nationwide implementation of SDM in daily practice at national, organizational and individual levels. Key recommendations include an intrinsic and supportive approach to help clinicians to adopt new behavior based on doing what is best for each individual patient, and the setting up of a 'national' program for a systematic approach to implementation involving all stakeholders. This means training clinicians and giving feedback on individual performance and empowering patients to actively participate in the decision-making process. Directors, managers and policymakers should work in parallel to design a healthcare system supportive of implementing SDM in the consulting room.

Frontrunners in SDM implementation mentioned that applying SDM makes their job more rewarding. This may be a driver to better engage clinicians in a process of sense making [32], so that they understand what SDM means for their daily work. It is clear that SDM implementation influences every aspect of clinical practice, from practical matters such as the scheduling of appointments, to more complex issues such as how clinicians feel about their profession or are able to work in a (multidisciplinary) team, in addition to how guidelines should be developed and applied. Effective SDM implementation is a evolving process, starting locally at the coalface of care. It demands an integrated multilevel approach that utilizes the mechanisms that innovators have shown to be effective.

The barriers for implementation we identified corroborate those that others have reported [16], [23]. Our results confirm that interventions targeting both patients and clinicians seem more promising than those targeting only one or the other [22]. Moreover, our study provides suggestions for helping clinicians understand what SDM really entails [2], and for increasing clinician support in order to facilitate meaningful SDM [33]. However, the frontrunners did not mention previously identified barriers such as time, competing demands from other medical 
problems and the psychological burden of deliberation. It is possible that innovators are highly motivated and have learned to effectively work around such barriers.

Next, we reinforce the earlier pleas for building systematic implementation strategies [15], [16], [17], [19], [20], [22], [23], [34]. Our findings will be useful for implementing the next steps in engaging both clinicians and patients in SDM [15], [17], [20], [33], and gaining a better understanding of the nature of professional and organizational resistance to SDM [12]. The goal is that SDM becomes an intrinsic part of a clinician's role. Ideally, SDM should be integrated in medical decision-making, shifting the paradigm towards a role in which coaching the patient in difficult decisions is key for clinicians [35], [36], and providing a counterbalance to the introduction of many standardized procedures and to some of the criticisms raised against evidence-based medicine [37].

Our recommendation to include SDM in the curricula and in inter-professional training programs, using reflective elements and real-time feedback on performance via recurrent audio, video, or real-life observations of consultations (i.e. using OPTION [38] or MAPPIN'SDM [25]), has already been found to be effective in improving SDM competencies [25].

Many strategies have been developed to increase the speed of implementation [39], [40] and yet, the uptake of SDM in daily practice has been slow [5]. Our findings underline that we need to better understand the impact of SDM on patients and clinicians in their particular working context [17], [41], [42], [43]. Our study also suggests the need for reorganizing processes in healthcare organizations, e.g. making changes in local care pathways and finding additional time for reflection and exploring patient values ('time-out'), even if this sometimes requires lengthier [5], or additional consultations [44].

We therefore propose that the effective implementation of SDM can be seen as a "team sport", rather than a simple trick that can be learned and applied to practice by individual clinicians. This comprises clear procedures tailored to the specific setting, procedures for setting the indication for SDM, timely prescribing patient decision aids, defining a menu of options rather than a single option in multidisciplinary (oncology) team meetings, delegating specific tasks 
within these teams, and safeguarding the second consultation for the preference and decision talks. Effective principles of collaborative [45] and small-scale learning [46] can help design strategies that are intrinsically rewarding and take current practice as a starting point for implementation at microsystem, team, organization and macro-levels. In order to accelerate learning about effective change, research projects should focus on how implementation initiatives perform in different contexts, for different groups of clinicians and patients.

\section{Strengths and limitations of this study}

We gathered data about implementation strategies from Dutch experts with varying backgrounds, using a combination of methods. This enhances the internal and external validity of our outcomes. However, some of the recommendations might be more relevant to the Dutch situation, i.e. the need to adapt local and national legislation regarding SDM. Second, our purposeful sampling predominantly selected pioneers in the area of SDM. We also had a high representation of frontrunners working in clinical practice. This is consistent with our sampling strategy and is not considered to be a limitation, but rather as useful in terms of appreciating what implementing SDM in daily practice requires. It has deepened our knowledge of effective approaches that can be used to support the implementation of SDM in a local context on the one-hand, and to align it with a nationwide approach on the other. It may have contributed to the high response rate for the interviews and focus groups, as innovators in the field may have been more positively inclined towards contributing to our study. Finally, the authors are also protagonists of SDM, and have been working for years to implement SDM. This could have caused a positive interpretation bias of the field notes of the interviews and focus groups.

Third, few patient advocates were present in our sample, which might have limited our ability to accurately reflect their views. However, the participating patient advocates were employed by two umbrella organizations for patient advocacy and represent a large body of patient stakeholders. 
Finally, the presentation of our findings (in subdivisions based on a theoretical framework for implementation [10]) was designed to be transparent, accurate and understandable. Before finalizing the results, every participant had the opportunity to read the draft report and to discuss it within their stakeholder group.

\subsection{Conclusion}

This exploratory study yielded a multilevel approach for the implementation of SDM in the Netherlands. A targeted multilevel approach such as shown in Table A.3 is needed to accelerate the implementation. As clinicians remain primarily responsible for the course of events in consultations, we expect that most progress will be made by learning how to effectively engage clinicians, influence their behavior, and alter their clinical pathways. Our sample of innovators helps us to understand how successful implementation works and to identify key components that can be used to engage clinicians in applying SDM. Frontrunners are relatively innovative and skilled in breaking through (system) barriers. To ensure that less motivated groups embrace SDM, additional efforts are needed. We therefore stress the importance of changing the socio-political system. Indeed, we call for the redesign of the entire system of incentives, and the structures and processes that inhibit deliberation and collaboration, from the ground up. SDM can potentially emerge as a key driver in healthcare reform becoming truly person-centered rather than system-driven.

\subsection{Practice implications}

Many Dutch key stakeholder groups - such as professional societies, patient organizations, healthcare insurance companies and government - have formulated specific ambitions to promote SDM. National government should take the lead in inviting these stakeholders to coordinate their activities on a national scale and help adapt legislation to promote SDM. Efforts to support the implementation of SDM should start bottom-up and leave room for fine tuning at a local level. The key focus should be on process redesign and professional behavior that 
supports applying SDM in daily practice in a specific context. Government and healthcare insurers can provide resources for initiatives to maximize the effect of SDM in daily practice, and promising initiatives can be coordinated on a national scale. Professional bodies should take the responsibility to teach clinicians how to coach patients, and work with patients on adapting guidelines and clinical pathways. Healthcare insurers can experiment with sensible and responsible ways of reimbursement and, together with patient organizations, empower citizens and patients to engage with their clinicians. Decision support tools should be made available via a central platform. All stakeholders need to put innovators in the spotlight and make clear that applying SDM enhances work satisfaction and improves the relationship between clinicians and patients. 


\section{Acknowledgments}

We thank Gonny ten Haaft (GH) for assisting in recruiting study participants and gathering, analyzing and interpreting the data, and Natalie Schols for critically reading the manuscript.

Experts in SDM, clinicians, patient representatives and healthcare insurers were involved in the project. We are grateful to all of the participants for their input in our project.

Author contributions: Two investigators (HV, GH) designed the study. HV obtained funding. Two investigators $(\mathrm{HV}, \mathrm{GH})$ coordinated the research activities: selection of the study participants and study design, data collection, data analysis, data interpretation, and writing of the report. All authors had full access to all of the data (including notes from interviews, focus group conferences and tables) and, can take responsibility for the integrity of the data and the accuracy of the data analysis. TW, DU, AS, LM and $\mathrm{CH}$ contributed to implementation of the study and data interpretation and approved the final report for publication. HV is the guarantor.

Funding: Research reported in this publication was funded by ZonMw, The Netherlands Organization for Health Research and Development.

Conflict of interests: The views presented in this publication are solely the responsibility of the authors and do not necessarily represent the views of ZonMw. The funder of the study approved the study concept and was allowed to propose participants for participating in interviews and focus groups.

Ethical approval: Ethical approval was not required as no patients were included in the study. All participants agreed to participate and to have their opinions and comments used for the research.

Data sharing: A background report with all names of participants and data tables can be accessed via the funders' website:

https://publicaties.zonmw.nl/fileadmin/documenten/DoelmatigheidsOnderzoek/2Rapport Verken ning Samen beslissen FINAL.pdf. De-identified data can be requested from the corresponding author at haskevanveenendaal@gmail.com. 
Transparency: The corresponding author (HV) affirms that the manuscript is honest, accurate, and a transparent account of the study being reported; that no important aspects of the study have been omitted; and that any discrepancies from the study as planned and registered have been explained. 


\section{References}

[1] T.C. Hoffmann, V.M. Montori, C. Del Mar, The connection between evidence-based medicine and shared decision making, J. Am. Med. Assoc. 312 (2014) 1295-1296. doi:10.1001/jama.2014.10186.

[2] G. Elwyn, M.A. Durand, J. Song, J. Aarts, P.J. Barr, Z. Berger, N. Cochran, D. Frosch, D. Galasiski, P. Gulbrandsen, P.K.J. Han, M. Härter, P. Kinnersley, A. Lloyd, M. Mishra, L. Perestelo-Perez, I. Scholl, K. Tomori, L. Trevena, H.O. Witteman, T. Van Der Weijden, A three-talk model for shared decision making: Multistage consultation process, BMJ. 359 (2017) 1-7. doi:10.1136/bmj.j4891.

[3] A.M. Stiggelbout, A.H. Pieterse, J.C.J.M. De Haes, Shared decision making: Concepts, evidence, and practice, Patient Educ. Couns. 98 (2015) 1172-1179. doi:10.1016/j.pec.2015.06.022.

[4] D. Stacey, F. Légaré, K. Lewis, M.J. Barry, C.L. Bennett, K.B. Eden, M. Holmes-Rovner, H. Llewellyn-Thomas, A. Lyddiatt, R. Thomson, L. Trevena, Decision aids for people facing health treatment or screening decisions, Cochrane Database Syst. Rev. 2017 (2017). doi:10.1002/14651858.CD001431.pub5.

[5] N. Couët, S. Desroches, H. Robitaille, H. Vaillancourt, A. Leblanc, S. Turcotte, G. Elwyn, F. Légaré, Assessments of the extent to which health-care providers involve patients in decision making: A systematic review of studies using the OPTION instrument, Heal. Expect. 18 (2015) 542-561. doi:10.1111/hex.12054.

[6] J.E. Squires, K. Sullivan, M.P. Eccles, J. Worswick, J.M. Grimshaw, Are multifaceted interventions more effective than single-component interventions in changing health-care professionals' behaviours? An overview of systematic reviews, Implement. Sci. 9 (2014) 152. doi:10.1186/s13012-014-0152-6.

[7] R. Grol, J. Grimshaw, From best evidence to best practice: effective implementation of 
change in patients' care, Lancet. 362 (2003) 1225-1230. doi:S0140-6736(03)14546-1 [pii].

[8] R. Glasgow, T. Vogt, S. Boles, Evaluating the public health impact of health promotion interventions: the RE-AIM framework., Am. J. Public Health. 89 (1999) 1322-1327. doi:10.2105/AJPH.89.9.1322.

[9] T. Greenhalgh, G. Robert, F. Macfarlane, P. Bate, O. Kyriakidou, Diffusion of innovations in service organizations: systematic review and recommendations, Milbank Q. 82 (2004) 581-629. doi:10.1111/j.0887-378X.2004.00325.x.

[10] M. Fleuren, K. Wiefferink, T. Paulussen, Determinants of innovation within health care organizations. Literature review and Delphi study, Int. J. Qual. Heal. Care. 16 (2004) 107-123. doi:10.1093/intqhc/mzh030.

[11] P. Nilsen, Making sense of implementation theories, models and frameworks, Implement. Sci. 10 (2015) 53. doi:10.1186/s13012-015-0242-0.

[12] G. Elwyn, D. Frosch, R. Thomson, N. Joseph-Williams, A. Lloyd, P. Kinnersley, E. Cording, D. Tomson, C. Dodd, S. Rollnick, A. Edwards, M. Barry, Shared decision making: A model for clinical practice, J. Gen. Intern. Med. 27 (2012) 1361-1367. doi:10.1007/s11606-012-2077-6.

[13] M. Edwards, M. Davies, A. Edwards, What are the external influences on information exchange and shared decision-making in healthcare consultations: A meta-synthesis of the literature, Patient Educ. Couns. 75 (2009) 37-52. doi:10.1016/j.pec.2008.09.025.

[14] I. Henselmans, M. Heijmans, J. Rademakers, S. van Dulmen, Participation of chronic patients in medical consultations: Patients' perceived efficacy, barriers and interest in support, Heal. Expect. 18 (2015) 2375-2388. doi:10.1111/hex.12206.

[15] N. Joseph-Williams, G. Elwyn, A. Edwards, Knowledge is not power for patients: A systematic review and thematic synthesis of patient-reported barriers and facilitators to 
shared decision making, Patient Educ. Couns. 94 (2014) 291-309.

doi:10.1016/j.pec.2013.10.031.

[16] F. Légaré, S. Ratté, K. Gravel, I.D. Graham, Barriers and facilitators to implementing shared decision-making in clinical practice: Update of a systematic review of health professionals' perceptions, Patient Educ. Couns. 73 (2008) 526-535. doi:10.1016/j.pec.2008.07.018.

[17] N. Joseph-Williams, A. Lloyd, A. Edwards, L. Stobbart, D. Tomson, S. Macphail, C. Dodd, K. Brain, G. Elwyn, R. Thomson, Implementing shared decision making in the NHS: lessons from the MAGIC programme, BMJ. 357 (2017) j1744. doi:10.1136/bmj.j1744.

[18] G. Elwyn, I. Scholl, C. Tietbohl, M. Mann, A.G. Edwards, C. Clay, F. Légaré, T. van der Weijden, C.L. Lewis, R.M. Wexler, D.L. Frosch, "Many miles to go ...”: a systematic review of the implementation of patient decision support interventions into routine clinical practice, BMC Med. Inform. Decis. Mak. 13 (2013) S14. doi:10.1186/1472-6947-13-S2S14.

[19] T. Van Der Weijden, H. Van Veenendaal, T. Drenthen, M. Versluijs, P. Stalmeier, M.K. Van Loon, A. Stiggelbout, D. Timmermans, Shared decision making in the Netherlands, is the time ripe for nationwide, structural implementation?, Z. Evid. Fortbild. Qual. Gesundhwes. 105 (2011) 283-288. doi:10.1016/j.zefq.2011.04.005.

[20] A.S. O'Malley, E.R. Carrier, E. Docteur, A.C. Shmerling, E.C. Rich, Policy Options to Encourage Patient-Physician Shared Decision Making, Policy Anal. 5 (2011) 1-10. http://www.collaborationhealthcare.com/9-20-11NIHCRShared-Decision-Making.pdf.

[21] F. Légaré, S. Turcotte, D. Stacey, S. Ratté, J. Kryworuchko, I.D. Graham, Patients' perceptions of sharing in decisions: A systematic review of interventions to enhance shared decision making in routine clinical practice, Patient. 5 (2012) 1-19. doi:10.2165/11592180-000000000-00000. 
[22] F. Légaré, D. Stacey, S. Turcotte, M.-J. Cossi, J. Kryworuchko, I.D. Graham, A. Lyddiatt, M.C. Politi, R. Thomson, G. Elwyn, N. Donner-Banzhoff, Interventions for improving the adoption of shared decision making by healthcare professionals., Cochrane Database Syst. Rev. 9 (2014) CD006732. doi:10.1002/14651858.CD006732.pub3.

[23] F. Légaré, P. Thompson-Leduc, Twelve myths about shared decision making, Patient Educ. Couns. 96 (2014) 281-286. doi:10.1016/j.pec.2014.06.014.

[24] N.T. Diouf, M. Menear, H. Robitaille, G. Painchaud Guérard, F. Légaré, Training health professionals in shared decision making: Update of an international environmental scan, Patient Educ. Couns. 99 (2016) 1753-1758. doi:10.1016/j.pec.2016.06.008.

[25] F. Geiger, K. Liethmann, D. Reitz, R. Galalae, J. Kasper, Efficacy of the doktormitSDM training module in supporting shared decision making. Results from a multicenter double - blind randomized controlled trial, (2017). doi:10.1016/j.pec.2017.06.022.

[26] M. Härter, N. Moumjid, J. Cornuz, G. Elwyn, T. van der Weijden, Shared decision making in 2017: International accomplishments in policy, research and implementation, Z. Evid. Fortbild. Qual. Gesundhwes. 123-124 (2017) 1-5. doi:10.1016/j.zefq.2017.05.024.

[27] M.Q. Patton, Enhancing the quality and credibility of qualitative analysis., Health Serv. Res. (1999). doi:http://dx.doi.org/10.4135/9781412985727.

[28] B.C. O'Brien, I.B. Harris, T.J. Beckman, D.A. Reed, D.A. Cook, Standards for Reporting Qualitative Research : A synthesis of Recommendations, Acad. Med. 89 (2014) 12451251. doi:10.1097/ACM.0000000000000388.

[29] M.Q. Patton, Qualitative evaluation and research methods, 2002. doi:10.1002/nur.4770140111.

[30] L.A. Palinkas, S.M. Horwitz, C.A. Green, J.P. Wisdom, N. Duan, K. Hoagwood, Purposeful Sampling for Qualitative Data Collection and Analysis in Mixed Method Implementation Research, Adm. Policy Ment. Heal. Ment. Heal. Serv. Res. 42 (2015) 
533-544. doi:10.1007/s10488-013-0528-y.

[31] T. van der Weijden, H. Post, P.L.P. Brand, H. van Veenendaal, T. Drenthen, L.A. van Mierlo, P. Stalmeier, O.C. Damman, A. Stiggelbout, Shared decision making, a buzzword in the Netherlands, the pace quickens towards nationwide implementation..., Z. Evid. Fortbild. Qual. Gesundhwes. (2017). doi:10.1016/j.zefq.2017.05.016.

[32] K.E. Weick, K.M. Sutcliffe, D. Obstfeld, Organizing and the Process of Sensemaking, Organ. Sci. 16 (2005) 409-421. doi:10.1287/orsc.1050.0133.

[33] S. Pollard, N. Bansback, S. Bryan, Physician attitudes toward shared decision making: A systematic review, Patient Educ. Couns. 98 (2015). doi:10.1016/j.pec.2015.05.004.

[34] F. Légaré, H.O. Witteman, Shared decision making: Examining key elements and barriers to adoption into routine clinical practice, Health Aff. (2013). doi:10.1377/hlthaff.2012.1078.

[35] S. Salloch, Who's afraid of EBM? Medical professionalism from the perspective of evidence-based medicine, Med. Heal. Care Philos. 20 (2017) 61-66. doi:10.1007/s11019-016-9726-1.

[36] R. Sennett, The Craftsman, Craftsm. V (2008) 336. doi:978-0-300-11909-1.

[37] J.P.A. loannidis, Hijacked evidence-based medicine: stay the course and throw the pirates overboard, J. Clin. Epidemiol. (2017). doi:10.1016/j.jclinepi.2017.02.001.

[38] G. Elwyn, a Edwards, M. Wensing, K. Hood, C. Atwell, R. Grol, Shared decision making: developing the OPTION scale for measuring patient involvement., Qual. Saf. Health Care. (2003). doi:10.1136/qhc.12.2.93.

[39] R.G. Tabak, E.C. Khoong, D.A. Chambers, R.C. Brownson, Bridging research and practice: Models for dissemination and implementation research, Am. J. Prev. Med. 43 (2012) 337-350. doi:10.1016/j.amepre.2012.05.024. 
[40] C.K.Y. Chan, B. Oldenburg, K. Viswanath, Advancing the Science of Dissemination and Implementation in Behavioral Medicine: Evidence and Progress, Int. J. Behav. Med. 22 (2015) 277-282. doi:10.1007/s12529-015-9490-2.

[41] G. Elwyn, I. Scholl, C. Tietbohl, M. Mann, A.G. Edwards, C. Clay, F. Legare, T. van der Weijden, C.L. Lewis, R.M. Wexler, D.L. Frosch, "Many miles to go ...”: a systematic review of the implementation of patient decision support interventions into routine clinical practice, BMC Med Inf. Decis Mak. 13 Suppl 2 (2013) S14. doi:10.1186/1472-6947-13S2-S14.

[42] G. Elwyn, D.L. Frosch, S. Kobrin, Implementing shared decision-making: consider all the consequences, Implement. Sci. 11 (2015) 114. doi:10.1186/s13012-016-0480-9.

[43] G. Elwyn, S. Wieringa, T. Greenhalgh, Clinical encounters in the post-guidelines era, Bmj. 3200 (2016) i3200. doi:10.1136/bmj.i3200.

[44] E.A.G. Joosten, L. DeFuentes-Merillas, G.H. De Weert, T. Sensky, C.P.F. Van Der Staak, C.A.J. De Jong, Systematic review of the effects of shared decision-making on patient satisfaction, treatment adherence and health status, Psychother. Psychosom. 77 (2008) 219-226. doi:10.1159/000126073.

[45] L.M.T. Schouten, M.E.J.L. Hulscher, J.J.E. v. Everdingen, R. Huijsman, R.P.T.M. Grol, Evidence for the impact of quality improvement collaboratives: systematic review, BMJ. 336 (2008) 1491-1494. doi:10.1136/bmj.39570.749884.BE.

[46] A. Lloyd, N. Joseph-Williams, A. Edwards, A. Rix, G. Elwyn, Patchy "coherence": using normalization process theory to evaluate a multi-faceted shared decision making implementation program (MAGIC), Implement. Sci. 8 (2013) 102. doi:10.1186/1748-59088-102. 
Table A.1 Backgrounds of participants. Values are expressed as numbers (percentages).

\begin{tabular}{|c|c|c|c|c|c|}
\hline Method & $\begin{array}{l}\text { Healthcare } \\
\text { professional }\end{array}$ & $\begin{array}{l}\text { Patient } \\
\text { advocate }\end{array}$ & Researcher & $\begin{array}{l}\text { Policy } \\
\text { maker }\end{array}$ & Other \\
\hline Interviews $(\mathrm{N}=43)$ & $14(33)$ & $3(7)$ & $15(35)$ & $7(16)$ & $4(9)$ \\
\hline \multicolumn{6}{|l|}{ Focus group } \\
\hline $1(N=24)$ & $5(21)$ & $2(8)$ & $6(25)$ & $10(42)$ & $1(4)$ \\
\hline $2(\mathrm{~N}=27)$ & $11(41)$ & $3(11)$ & $8(30)$ & $5(19)$ & $0(0)$ \\
\hline Total $(\mathrm{N}=51)$ & $16(31)$ & $5(10)$ & $14(27)$ & $15(29)$ & $1(2)$ \\
\hline $\begin{array}{l}\text { Written comments on the } \\
\text { consultation round }(\mathrm{N}=19)\end{array}$ & $2(11)$ & $2(11)$ & $12(63)$ & $3(16)$ & $0(0)$ \\
\hline Total number of participants & 32 & 10 & 41 & 25 & 5 \\
\hline
\end{tabular}


Table A2. Perceived barriers for the implementation of SDM in random order per implementation level $(\mathrm{C}=$ clinicians; $\mathrm{P}=$ patients; $\mathrm{M}=$ policy makers; $\mathrm{SDM}=$ Shared decision making $)$

\begin{tabular}{|c|c|}
\hline Implementation level & Barriers \\
\hline $\begin{array}{l}\text { 1. Concept of SDM } \\
\text { itself }\end{array}$ & 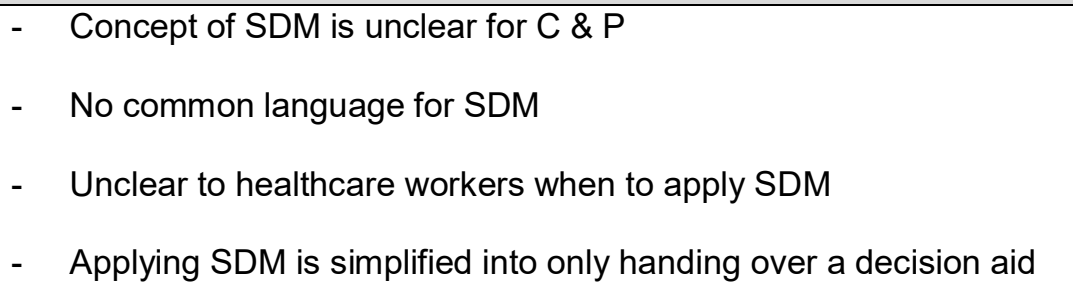 \\
\hline $\begin{array}{l}2 . \\
\text { a. Healthcare } \\
\text { professional }\end{array}$ & $\begin{array}{ll}\text { - } & \text { Negative attitude towards SDM } \\
\text { - } & \text { Misjudgement of patient preferences } \\
\text { - } & \text { Lack of knowledge about how to apply SDM } \\
\text { - } & \text { Lack of ability \& skills in relation to applying SDM } \\
\text { - } & \text { No recognition that SDM is not applied ('we are already doing it') }\end{array}$ \\
\hline b. Patient & $\begin{array}{l}\text { - } \quad \text { Lack of awareness that multiple options exist } \\
\text { - } \quad \text { Lack of initiative in decision making } \\
\text { - } \quad \text { Fear of P to be seen by } C \text { as 'someone causing trouble' } \\
\text { - } \quad \text { One of three P has low health literacy } \\
\text { - } \quad \text { Relative knowledge backlog in relation to P }\end{array}$ \\
\hline $\begin{array}{l}\text { 3. Organisational } \\
\text { context }\end{array}$ & $\begin{array}{ll}\text { - } & \text { Lack of role models amongst peers of } C \\
\text { - } & \text { Lack of team support for } C \\
\text { - } & \text { Lack of unambiguous information }\end{array}$ \\
\hline $\begin{array}{l}\text { 4. Socio-political } \\
\text { context }\end{array}$ & $\begin{array}{ll}\text { - } & \text { Lack of support from M } \\
\text { - } & \text { Lack of reward from external bodies } \\
\text { - } & \text { Lack of flexibility in relation to applying SDM in national guidelines } \\
\text { - } & \text { Availability of high quality decision aids is fragmented } \\
\text { - } & \text { Quality instruments that C use are not aligned } \\
\text { - } & \text { SDM is part of existing act (WGBO), but lack of maintenance }\end{array}$ \\
\hline
\end{tabular}


Table A.3 Prioritized strategies for the implementation of SDM

\begin{tabular}{|c|c|}
\hline $\begin{array}{l}\text { Element for imple- } \\
\text { mentation agenda }\end{array}$ & $\begin{array}{l}\text { Strategy (level of implementation: } 1=\text { concept of } \mathrm{SDM}, 2=\text { health professional and/or patient, } 3=\text { organizational context and } 4=\text { socio- } \\
\text { political context) }(\mathrm{Stakeholder} \text { involvement: } \mathrm{PB}=\text { professional bodies, } \mathrm{PO}=\text { patient organizations, } \mathrm{HI}=\text { healthcare insurance companies, GO } \\
=\text { government, } \mathrm{LM}=\text { local (quality) managers, } \mathrm{RI}=\text { research institutes) }\end{array}$ \\
\hline $\begin{array}{l}\text { 1. Integrated } \\
\text { programmatic } \\
\text { approach to build } \\
\text { intrinsic motivation }\end{array}$ & $\begin{array}{l}\text { - Implement SDM via an integrated 'national' program to facilitate the connection of fragmented initiatives, increase critical mass and speed } \\
\text { up the exchange of lessons learned regarding applied implementation strategies at national level (4) (PB, PO, HI, GO, LM, RI). } \\
\text { - Send a repetitive and consistent message that engages clinicians and patients to practice SDM and to facilitate a receptive culture in } \\
\text { which SDM is perceived as usual practice (1,2)(PB, PO, HI, GO, LM). } \\
\text { - } \quad \text { Motivate clinicians to relinquish old habits and change care processes in order to better accommodate individual patient preferences, both } \\
\text { in their team and in their organization (2) (PB, PO, LM). Place incentives accordingly (4) (PB, PO, HI, GO, LM). } \\
\text { - } \quad \text { Incorporate SDM into professional curricula and inter-professional training programs (2, 4) (PB, LM). } \\
\text { - } \quad \text { Monitor the progress of implementation and continuously connect the initiatives of professional bodies, patient organizations and } \\
\text { healthcare insurance companies (4) (PB, PO, HI, LM). } \\
\text { - } \quad \text { Adapt quality instruments, professional role descriptions, financial incentives and technological innovation (3, 4) (PB, HI, GO, LM). } \\
\text { - } \quad \text { Offer legitimation and support via research institutes and government, and collaborate with industries (4) (PB, PO, GO, RI). . }\end{array}$ \\
\hline $\begin{array}{l}\text { 2. Training and } \\
\text { implementation of } \\
\text { SDM in routine } \\
\text { practice }\end{array}$ & $\begin{array}{l}\text { - Set up a follow-on series of implementation initiatives to seek ways to maximize the effect of SDM in clinical practice (2), covering the four } \\
\text { implementation levels, and targeting issues relevant at the local context, including management support and ownership by clinicians (1, } 2 \text {, } \\
\text { 3, 4) (PB, PO, HI, GO, LM). } \\
\text { - Evaluate the experiments prospectively in order to better match the design of implementation support with the specific contexts in which } \\
\text { they are applied (4) (PB, PO, LM, RI). } \\
\text { - Utilize existing professional exchange structures to reinforce knowledge sharing }(2,4)(\mathrm{PB}) \text {. } \\
\text { - Pay special attention to process (re)design, including time-outs for patients in order to process information (3) (PB, PO, LM, RI). } \\
\text { - Test solutions for situations in which SDM may lead to loss of income for (some of the) clinicians in the organization (4) (HI, GO, LM, RI). } \\
\text { - Implement training methods that include reflective elements and real-time feedback on the clinicians' performance (2) (PB, LM). }\end{array}$ \\
\hline $\begin{array}{l}\text { 3. Stimulating the } \\
\text { empowerment of } \\
\text { patients and citizens }\end{array}$ & $\begin{array}{l}\text { - Help citizens and patients prepare for consultations with their clinicians, especially people with low health literacy }(1,2)(\mathrm{PB}, \mathrm{PO}, \mathrm{HI}, \mathrm{GO}) \text {. } \\
\text { - Make high-quality patient decision-making support tools available on a central public platform and give access to patient records (1) (PB, } \\
\text { PO, HI, GO). } \\
\text { - Stimulate the involvement of patients at micro-, meso- and macro-levels, before, during and after implementation }(1,2,3,4)(\mathrm{PB}, \mathrm{PO}, \mathrm{HI} \text {, } \\
\mathrm{GO}, \mathrm{LM}) \text {. }\end{array}$ \\
\hline $\begin{array}{l}\text { 4. Creating a } \\
\text { rewarding socio- } \\
\text { political context }\end{array}$ & $\begin{array}{l}\text { - Employ ground-up leadership by managers and policy makers within the context of scarcity in finance, resources, and time to make sure } \\
\text { that the implementation of SDM is not held back by logistical, financial, and administrative factors }(3,4)(G O, L M) \text {. } \\
\text { - Adjust consultation time in line with patients' individual needs and pay attention to lack of reimbursement for time spent on SDM (4) (PB, } \\
\text { HI, GO, LM). } \\
\text { - Anticipate budget shifts, organize the redesign of care pathways and ICT, redistribute tasks between team members, and allow flexibility } \\
\text { with regard to national guidelines and other regulations that are imposed by external stakeholders }(3,4)(P B, H I, G O, L M) \text {. }\end{array}$ \\
\hline
\end{tabular}

